\title{
AEU PROPUOT AEWS
}

3-Chip Microscope Video Camera with Built-In Digital Image Enhancement

The DEI-750 utilizes $3 \frac{1}{2} \mathrm{CCD}$ sensors to produce 750 lines of horizontal resolution for true color reproduction and increased detail recognition.

The camera's real-time digital image enhancement greatly increases the image information from the source. A 2-D convolution filter, digital contrast, and brightness circuits increase apparent resolution to permit visual display of out-of focus low contrast images. On-chip integration enables exposure for up to 4 seconds for weak fluorescence sample imaging. Long exposure increases camera sensitivity to 0.02 lux

The remote video controller replaces the need for an additional microprocessor. the controller contains builtin memory that allows high speed image digitation to deliver video rate or freeze-frame images. All camera functions are controlled through the full size computer-style keyboard. This keyboard also functions as a video character generator allowing on-screen recording of titles (up to 192 alpha numeric characters)

Color and $\mathrm{B} N$ video outputs allow simultaneous delivery of a monochrome 750 line resolution image as well as providing true color images using RGB or Y/C outputs. In addition, the DEl-750 is compatible with any monochrome image processing system. Multiple video outputs on the back of the controller enable simultaneous use of video printers, frame grabbers, or monitors.

For further information, contact Optronics Engineering at (805) $968-3568$. Circle Reader Inquiry $\# 32$

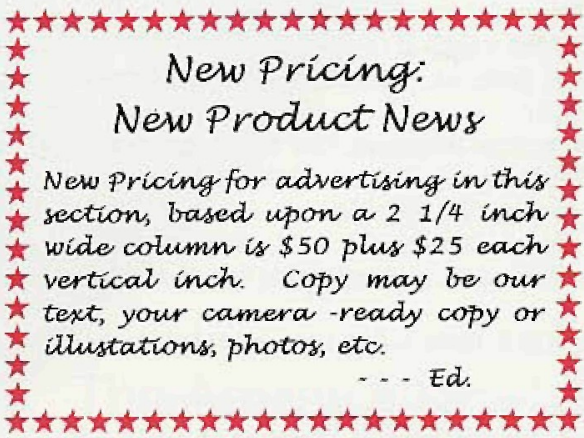

\section{LEICA ULTRACUT UCT}

Leica is pleased to introduce the new LEICA ULTRACUT UCT ultramicrotome for electron microscopy sample preparation, designed to meet the precise requirements of the industrial/materials markets. Since the LEICA ULTRACUT UCT is designed for stringent indusirial demands, it is ideal for biological applications as well and will exceed your performance expectations

The LEICA ULTRACUT UCT features automatic feed in $1 \mathrm{~nm}$ increments from 1 to $100 \mathrm{~nm}$. The variable cutting speed can be finitely controlled to $0.05 \mathrm{~mm}$ per second.

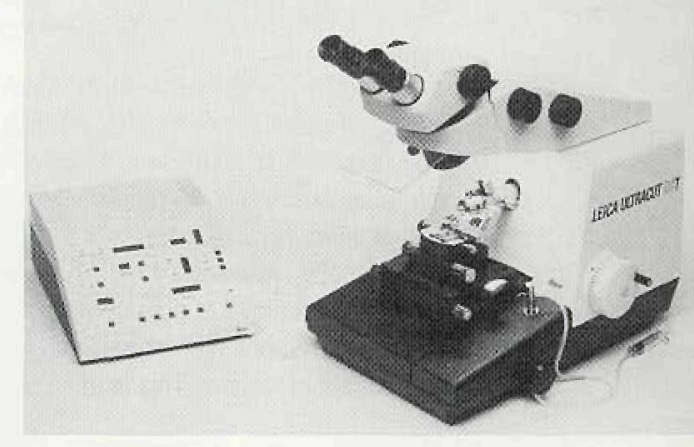

The LEICA ULTRACUT UCT takes into account the needs and demands of today's ulitamicrotome user and makes use of the latest innovations and technological advances in engineering and electronics. The compact space saving design and separation of control unit and sectioning instrument has many advantages and contributes to the instrument's outstanding performance. All key functions of the microtome, even the motorized approach of knife to specimen, can be operated from the separate control unit.

Like all Leica ultramicrotomy products, the LEICA ULTRACUT UCT is easy to use and operate For more information, call 1-800-248-0123 today! Circle reader inquiry \#32

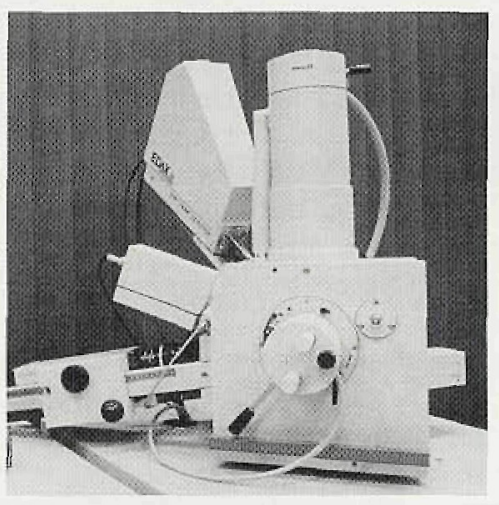

New Micro-Diffraction Facility With Philips SEM

Buyers of the new Philips' XL30 Scanning Electron Microscope (SEM) can now add a micro-diffraction facility, thanks to a new module just introduced by Philips Electron Optics. By interfacing the electron backscatter pattern (EBSP) module with the SEM, it's possible to record diffraction patterns of individual crystallites of sizes below $1 \mu \mathrm{m}$. EBSPs of virtually all crystalline materials can be recorded provided that the crystallinity extends all the way to the surface. Besides small crystallites, the EBSP technique is very suited for analyzing electron-polished samples and thin films.

An EBSP is a highly symmetrical arrangement of bands of warious widths which cross in poles. this pattern, a modulation of intensity of backscattered electrons, is projected onto a fluorescent screen located close to the sample, and recorded using a highly sensitive Silicon Intensified Target (SIT) camera in the module. From the widths and positions of these bands, information can be deduced on the symmetry, orientation and even the perfection of a crystal. This makes the EBSP technique particularly suitable for highly local phase analysis and for local texture analysis.

Designed to be fully integrate into Philips' XL30 SEM, the detector is supported by COS-software for indexing of the recorded patterns. This software runs on the SEM computer under Windows, and automatically shares data with the microscope's main control program. For additional information contact Philips Electronic Instruments at (201)5293800, Fax: (201)529-2252. Circle Reader Inquiry \#33

\section{$+\frac{10}{10}$ \\ NORAW/Tracor Northern EDS Repair}

Factory and field trained personnel with over 35 years total experience, located in the the Midwest, Southeast and on the West Coast, specializing in TN2000 and TN5500 repair, detector upgrades, data storage, imaging hardware and peripheral output devices - and used equipment resale.

Choose from a full maintenance or parts only contract, or on-demand service - at rates normally a fraction of others

For further information, contact Doug Connors at:

\section{T Analyzer Service}

7897 Highway 19

Dane, WI 53529
Tel.: (608)798-2005

Fax: (608)798-1675

\section{USED EOUIPMEAT rOR SnLE}

P Philips CM12 TEM with integral microprocessor control and readout $\pm 60^{\circ}$ eucentric goniometer stage with twin objective lens. Includes operating software and EDAX qualitative EDS system. Purchase date 1988 with little use. Like new. Has been under Philips service. To make offer, call: (800)464-7676 and ask for Jay.

8 HITACHI HU 11B - still under vacuum; in OK working order and with lots of spare parts. Any offer will be considered. Contact Dr. M. Gillott, University of Wisconsin - Wilwaukee at email: magem@alpha2 uwm edu

a LEITZ MICROSCOPES AND MICROTOMES - Former Leitz dealer has a good selection of bio scopes for routine and research. DIALUX, ORTHOLUX, ORTHOPLAN, 1512. FAX us for complete listing of instruments as well as REPAIR PARTS FOR LEITZ. Scopes or parts? (301)762-8453 (Maryland).

- JEOL 35C SEM with Tracor Northern TN2000 EDS and accessories. 1979+ - $\$ 8,500$. Call Steve Emmert or Sam Newhouse at (816)796-4000 (KC area)

- MILITARY RESEARCH LAB IS CLOSING - Military contractor is selling at drastically reduced prices its Sorvall ultramicotome, refrigerated and benchtop microtomes, sliding microtome, Tissue Tech embedding center, stereo microscopes, Joyce Loebl microdensitometer and LECO sulfer analyzer. For specification sheets call: $(202) 544-0836$ 